\title{
Inhibition of the phytopathogenic fungi Curvularia lunata BM and Ganoderma sp. TB4 by antifungal compounds produced by Bacillus siamensis LDR grown on hanjeli (Coix lacryma-jobi L.) starch
}

\author{
Iman Santoso ${ }^{1,2}$, Qonita Gina Fadhilah ${ }^{1}$, Syella Dwi Safitri ${ }^{1}$, Sri Handayani ${ }^{3}$, Andi Eko Maryanto ${ }^{1}$ \\ Yasman Yasman ${ }^{1,4}$ \\ 1 Department of Biology, Faculty of Mathematics and Natural Sciences (FMIPA), Universitas Indonesia, Depok, Indonesia \\ 2 Center of Excellence for Indigenous Biological Resources-Genome Studies (CoE IBR-GS), FMIPA, Universitas Indonesia, Depok, Indonesia \\ 3 Department of Chemistry, FMIPA, Universitas Indonesia, Depok, Indonesia \\ 4 Research Group of Metabolomics and Chemical Ecology, Department of Biology, FMIPA, Universitas Indonesia, Depok, Indonesia \\ Corresponding author: Iman Santoso (iman-s@ui.ac.id)
}

Received 6 January 2022 • Accepted 15 February 2022 • Published 7 March 2022

Citation: Santoso I, Fadhilah QG, Safitri SD, Handayani S, Maryanto AE, Yasman Y (2022) Inhibition of the phytopathogenic fungi Curvularia lunata BM and Ganoderma sp. TB4 by antifungal compounds produced by Bacillus siamensis LDR grown on hanjeli (Coix lacryma-jobi L.) starch. Pharmacia 69(1): 203-210. https://doi.org/10.3897/pharmacia.69.e80180

\begin{abstract}
Bacillus siamensis LDR was tested for its potential as a biocontrol agent against the phytopathogenic fungi Curvularia lunata BM and Ganoderma sp. TB4. Fermentation of B. siamensis LDR for the production of antifungal compound was performed in modified CzapexDox broth using hanjeli (Coix lacryma-jobi L.) starch as carbon source. The Bacillus siamensis LDR inoculum was $10^{5} \mathrm{CFU} / \mathrm{mL}$, and fermentation was conducted for up to 16 days. Antibiosis assay conducted to test the antifungal activity of filtrate medium. The results showed inhibition of C. lunata BM and Ganoderma sp. TB4 were $47.08 \%$ and $85.99 \%$, respectively on $14^{\text {th }}$ day of fermentation. Antifungal assay of the crude extract from filtrate medium revealed growth inhibition of C. lunata BM (60.70\%) and Ganoderma sp. TB4 (65.25\%). Thin layer chromatography of the crude extract revealed pink-colored spots indicative of lipopeptide compounds. Analysis of the crude extract by ultraperformance liquid chromatography-mass spectrometry was tentatively identified as iturin A, bacillomycin F, and surfactin.
\end{abstract}

\section{Keywords}

antifungal compound, Bacillus siamensis LDR, biocontrol agent, phytopathogenic fungi

\section{Introduction}

Agriculture is one of the most important national economic sectors in Indonesia. Palm oil and coffee are important agricultural commodities that contribute to
Indonesian's foreign exchange (FAO 2017). Nevertheless, the agricultural sector is facing many problems, especially plant disease caused by infections of pathogens, such as fungi. Fungal infections can adversely affect agricultural products and lower their economic 
value (Almeida et al. 2019). The most devastating phytopathogenic fungi affecting palm oil plantations are Ganoderma sp. (Hushiarian et al. 2013; Peterson 2019) and Curvularia sp. (Sunpapao et al. 2014; Agustika et al. 2019). Ganoderma sp. infection on the basal stems of palm tree (Elaeis guineensis Jacq.) is a serious problem that leads to stem rot and has significant negative impacts on oil palm production (Rees et al. 2009; Naher et al. 2013). Curvularia sp. attacks palm seedlings and cause leaf blight or leaf spots disease (Agustika et al. 2019), and it also infects other important crops, such as corn (Garcia-Aroca et al. 2018) and rice (Majeed et al. 2015). Therefore, the diseases caused by fungal infection should be controlled.

One sustainable control strategy is to use bacteria as biocontrol agents (Tiwari et al. 2019; Dame et al. 2021), as these can replace synthetic or chemical pesticides that can cause problems in human health and pollute the earth's ecosystems (Shafi et al. 2017). The use of chemicals can also threaten the survival of non-target organisms (Prapagdee et al. 2008); therefore, the use of bacteria as biocontrol agents is an environmentally friendly approach for overcoming fungal infections in agricultural plantations. One promising bacterial genus is Bacillus, which are major plant growth-promoting bacteria (PGPB) known to promote and protect plant growth. Bacillus spp. produce many enzymes and bioactive compounds, including antifungal compounds. The antifungal compounds belong to cyclic lipopeptides biosurfactant compounds, such as iturin, fengycin, and surfactin (Dame et al. 2021). The antifungal compounds contribute to their function as biocontrol agents (Shafi et al. 2017; Dame et al. 2021). Bacillus cells have thick peptidoglycan walls and produce endospores (Akinrinlola et al. 2018; Tiwari et al. 2019), allowing these bacteria to survive under unfavorable environmental conditions (Radhakrishnan et al. 2017; Tiwari et al. 2019). Consequently, Bacillus spp. have longer viability compared to Gram-negative or non-endospore bacteria.

In the present research, B. siamensis LDR isolated from coconut peat was evaluated for its antifungal compounds using an antibiosis assay (Santoso et al. 2021a). This Bacillus species has shown antagonistic activity against several fungal pathogens, such as Aspergillus niger (Santoso et al. 2021a), Colletotrichum siamense KA (Fadhilah et al. 2021), Fusarium sp., Chaetomium globosum InaCC F228, Ganoderma sp. TB 4 (Santoso et al. 2021b), A. clavatus, A. flavus, A. tamarii (Pertiwi et al. 2021), and C. lunata BM (Safitri et al. 2021). The aim of this research was to evaluate the possibility of using starch from hanjeli (Coix lacryma-jobi L.) as a local carbon source in the bacterial fermentation medium. The other aims were to extract the antifungal compounds produced by $B$. siamensis LDR and to characterize and identify them using thin layer chromatography (TLC) and ultraperformance liquid chromatography-mass spectrometry (UPLC-MS).

\section{Materials and methods}

\section{Microorganisms}

Bacillus siamensis LDR and fungal phytopathogen, C. lunata BM and Ganoderma sp. TB4 were provided from Laboratory of Microbiology, Department of Biology, Faculty of Mathematics and Natural Sciences, Universitas Indonesia. The microorganisms were purified using a quadrant streak method on potato dextrose agar (PDA) medium. The pure culture of microorganisms were maintained in PDA medium.

\section{Growth of Bacillus siamensis LDR}

The Bacillus siamensis LDR culture was grown in modified Czapex-Dox broth (CDB) medium containing $3 \mathrm{~g} \mathrm{NaNO}_{3}$, $1 \mathrm{~g} \mathrm{~K}_{2} \mathrm{HPO}_{4}, 0.5 \mathrm{~g} \mathrm{MgSO}_{4}, 0.5 \mathrm{~g} \mathrm{KCl}, 0.01 \mathrm{~g} \mathrm{FeSO}_{4}, 15 \mathrm{~g}$ agar (Kusanggraeni et al. 2021) and supplemented with $2 \mathrm{~g}$ hanjeli as a carbon source in $1,000 \mathrm{~mL}$ distilled water. The modified CDB medium was inoculated with $10^{5} \mathrm{CFU} / \mathrm{mL}$ B. siamensis LDR, and bacterial growth was measured at 7 and 14 days using total plate counts (TPC).

\section{Fermentation of antifungal compounds}

The fermentation of antifungal compounds by B. siamensis LDR was performed in the modified CDB medium containing hanjeli starch. A $1 \%(\mathrm{v} / \mathrm{v})$ cell suspension of B. siamensis LDR was inoculated into $200 \mathrm{~mL}$ modified CDB medium and incubated for 12, 14, and 16 days. After incubation, the medium was centrifuged at $2,000 \mathrm{~g}$ for 20 min to obtain a cell-free filtrate, which was assumed to contain antifungal compounds produced by $B$. siamensis LDR. The cell-free filtrate was used to dissolve PDA powder to make a PDA-filtrate medium for the antibiosis assay.

\section{Antibiosis agar assay}

The antibiosis agar assay was conducted to determine the antifungal activity of compounds produced by $B$. siamensis LDR. The antibiosis agar assay was performed using the paper disk method for C. lunata BM and the agar plug method for Ganoderma sp. TB4. Spores of C. lunata $\mathrm{BM}$ in PDA medium were suspended in sterile distilled water, $10 \mu \mathrm{L}$ of the spore suspension was inoculated to a paper disk ( $6 \mathrm{~mm}$ ), and the paper disk was placed in the center of a plate containing the PDA-filtrate medium. An agar plug (Ø $5 \mathrm{~mm}$ ) of Ganoderma sp. TB4 was placed in the center of a plate containing the PDA-filtrate medium. As a control, a paper disk containing spores of $C$. lunata $\mathrm{BM}$ and an agar plug of Ganoderma sp. TB4 were placed on normal PDA medium.

The antibiosis agar plates were incubated for 5 days, and then the antifungal activity of $B$. siamensis LDR was tested by determining the inhibition of fungal growth. The diameter of the fungal colony was measured using caliper and the inhibition was calculated according to Hussain 
and Khan (2020) as the growth inhibition rate (GIR), where D1 is the diameter of the controlled fungal colony and $\mathrm{D} 2$ is the diameter of the threatened fungal colony.

$$
\operatorname{GIR}(\%)=\frac{D 1-D 2}{D 1} \times 100 \%
$$

\section{Production and extraction of antifungal compound}

A fourteen-day-old B. siamensis LDR in modified CDB medium was used for the extraction of antifungal compounds. The medium was centrifuged at 10,000 $\mathrm{g}$ for $10 \mathrm{~min}$ at $30^{\circ} \mathrm{C}$ to obtain a cell-free filtrate medium. The $\mathrm{pH}$ of the cell-free filtrate was adjusted to $\mathrm{pH} 2.0$ with 10 $\mathrm{N} \mathrm{HCl}$ and stored overnight at $4{ }^{\circ} \mathrm{C}$ (Hussain and Khan 2020). The resulting precipitate was collected by centrifugation at $10,000 \mathrm{~g}$ for $10 \mathrm{~min}$ at $4{ }^{\circ} \mathrm{C}$ and then mixed and shaken vigorously with chloroform:methanol $(2: 1, \mathrm{v} / \mathrm{v})$ at room temperature (Hussain and Khan 2020). The solution mixture was left until the solvent and precipitate were separated. The solvent was separated and evaporated at $40{ }^{\circ} \mathrm{C}$ to obtain the crude extract. The crude extract was dissolved in methanol to obtain a 4,500 ppm extract solution. The extract solution was sterilized using a syringe filter $(0.45 \mu \mathrm{m})$ before use in antifungal extract assay.

\section{Antifungal assay of the crude extract}

The antifungal activity of the crude extract from B. siamensis LDR was assayed on PDA using the paper disk method. Spores of C. lunata BM were suspended in sterile distilled water, and $10 \mu \mathrm{L}$ spore suspension was inoculated onto sterile paper disks, which were then placed in the center of each PDA plate. An agar plug of Ganoderma sp. TB4 was placed in the center of another set of PDA plates. The antifungal extract $(100 \mu \mathrm{L})$ was inoculated onto paper disks and placed on each plate $3 \mathrm{~cm}$ away from the edge of the C. lunata BM and Ganoderma sp. TB4 isolates. Methanol $(100 \mu \mathrm{L})$ was used as a control. The inoculated plates were incubated for 5 days for C. lunata BM and 10 days for Ganoderma sp. TB4. The antifungal activity was determined by the inhibition of growth of the fungal phytopathogen and was represented as the GIR.

\section{Antifungal compound characterization and identification}

The crude extract from $B$. siamensis LDR was characterized by TLC to detect the lipopeptide compounds suspected to act as antifungal compounds. Silica gel 60 F254 (Merck) was used as the stationary phase, and isopropanol: acetic acid: water (5:1:1) (v/v) was used as the mobile phase (Habib et al. 2020). The extract was spotted on the TLC plate, run for 30 min in the solvent and dried. The TLC plate was sprayed with water to observe the lipid moiety contained in the lipopeptide (Meena et al. 2018) and to detect protein moiety in the lipopeptide, the TLC plate was sprayed with $0.2 \%$ ninhydrin reagent and placed in the oven at $110^{\circ} \mathrm{C}$ for $20 \mathrm{~min}$. The pink spot on TLC plate was indicated protein moiety, meanwhile white spot was indicated lipid moiety in the lipopeptide compounds (Meena et al. 2018; Hussain and Khan 2020).

The crude extract was also characterized by UPLC-MS by separation on a C18 $(1.8 \mu \mathrm{m} 2.1 \times 100 \mathrm{~mm})$ HSS column (ACQUITY UPLC HSS, Waters, USA) using a mobile phase consisting of water and $5 \mathrm{mM}$ ammonium formate (solvent A) and acetonitrile and $0.05 \%$ formic acid (solvent B) at a flow rate of $0.2 \mathrm{~mL} / \mathrm{min}$ for $23 \mathrm{~min}$. The separated compounds were then analyzed by MS (Xevo G2-S Q-TOF, Waters, USA) using electrospray ionization in positive mode and a mass analysis range of 50$1200 \mathrm{~m} / z$. The operating parameters were collision $4 \mathrm{~V}$ and a ramp collision of 25-60 V.

\section{Results and discussion \\ Growth of Bacillus siamensis LDR}

Bacillus siamensis LDR grew well in the modified CDB medium with $0.2 \%$ hanjeli starch as the carbon source. The cell population increased to $3.5 \times 10^{7} \mathrm{CFU} / \mathrm{mL}$ after 7 days of incubation, and the cell population remained relatively constant $\left(4 \times 10^{7} \mathrm{CFU} / \mathrm{mL}\right)$ at 14 days of incubation, indicating that the cells had achieved the stationary phase. Bacillus siamensis LDR has been reported to produce amylase, which can hydrolyze various types of starch (Kusanggraeni et al. 2021), including hanjeli starch (Safitri et al. 2021). This ability allowed B. siamensis LDR to grow well in the modified CDB medium. According to Corke et al. (2016), hanjeli contains nutritious substances, such as starch, protein, and lipids, as well as other micronutrients, such as phosphate, magnesium, and zinc. Hanjeli also contains niacin, thiamine, and riboflavin (Mulyono et al. 2019). The starch, protein, and fat contained in hanjeli are up to $68 \%, 15.6 \%$, and $9 \%$, respectively (Tensiska et al. 2021). Therefore, the hanjeli starch can substitute for the potato starch used in commercial culture media.

Hanjeli starch is a complex carbohydrate consisting of both amylose and amylopectin components. Corke et al. (2016) reported that hanjeli starch contains about 15.925.8\% amylose. Amylose is considered a difficult compound to degrade (Wang et al. 1999); therefore, the metabolism of hanjeli starch will be gradual and it should support the growth of B. siamensis LDR for quite a long time. Antifungal compounds can therefore be produced using modified CDB containing hanjeli starch. Safitri et al. (2021) also reported that $B$. siamensis LDR has antagonistic activity against Ganoderma sp. TB4 and C. lunata BM when grown on modified Czapex-Dox agar (CDA) medium.

\section{Antibiosis agar assay}

The results of the antibiosis assay of B. siamensis LDR are presented in Table 1 . The diameters were smaller for the colonies of C. lunata BM and Ganoderma sp. TB4 grown on the PDA-filtrate medium than on the control PDA 
medium. Both fungi seemed to be inhibited by antifungal compounds produced by B. siamensis LDR and contained in the modified $\mathrm{CDB}$ medium. The percentage inhibition ranged from $44.14 \%$ to $47.08 \%$ for C. lunata BM and from $51.98 \%$ to $85.99 \%$ for Ganoderma sp. TB4. The highest percentage inhibition on both fungi were observed on PDA-filtrate containing $14^{\text {th }}$ day of filtrate fermentation.

Antifungal compounds are commonly produced during the stationary phase when nutrients are depleted (Horak et al. 2019). Kumar et al. (2012) reported that the maximum production of antifungal compounds was achieved at the end of the stationary phase. Nevertheless, a longer fermentation time can decrease the antifungal activity (Kumar et al. 2012) due to degradation, re-utilization, or conversion of the antifungal compounds (Horak et al. 2019) by B. siamensis LDR.

The results of $B$. siamensis LDR growth suggested that the antifungal compounds might already be produced by 7 days of fermentation. The antibiosis assay at 12 days showed inhibition of fungal growth and greater inhibition at14 days, probably due to an accumulation effect. Beyond 14 days, however, the levels of antifungal compounds tended to decrease, as indicated by the assay conducted at 16 days. The growth inhibition of C. lunata BM is presented in Fig. 1, and that of Ganoderma sp. TB4 is presented in Fig. 2.

\section{Antifungal assay of the crude extract}

The antifungal activity of the crude extract was assayed based on the results of the antibiosis assay, which indica-

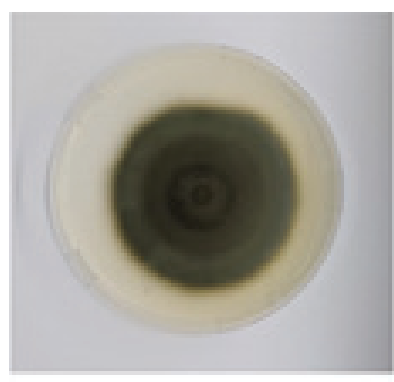

A

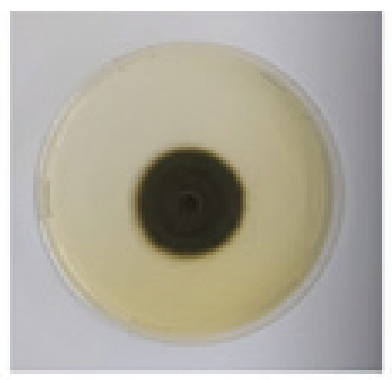

B

ted that 14 days of incubation gave the highest percentage inhibition against the two fungal pathogens tested. The results of the antifungal assay using the crude extract of $B$. siamensis LDR are presented in Fig. 3. The crude extract inhibited the growth of both C. lunata BM and Ganoderma sp. TB4, indicating that an antifungal compound had been extracted successfully from the modified CDB medium. The percentage inhibition was up to $60.70 \%$ for C. lunata BM and up to $65.25 \%$ for Ganoderma TB4 (Table 2).

The percentage inhibition obtained by antifungal assay using the crude extract (Table 2) was higher than the percentage inhibition achieved with the antibiosis assay on the PDA-filtrate medium (Table 1). This difference probably reflects the increased purity of the extracted antifungal compound, which meant that the compound was more concentrated in the antifungal assay than in the antibiosis assay. Abdallah et al. (2015) also found that the percentage inhibition of fungal growth was higher in antifungal assay performed with the extracted compound than with a cell-free filtrate of Bacillus spp.

\section{Antifungal compound characterization and identification}

The antifungal compounds present in the crude extract of $B$. siamensis LDR were detected using TLC. Spraying the TLC plate with water revealed a white spot (Fig. 4a), indicating a lipid moiety in the compound (Meena et al. 2018); meanwhile spraying the TLC plate with $0.2 \%$ ninhydrin revealed

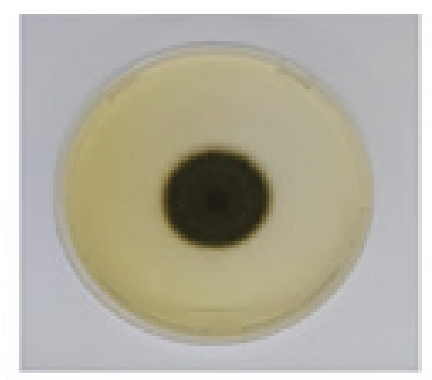

C

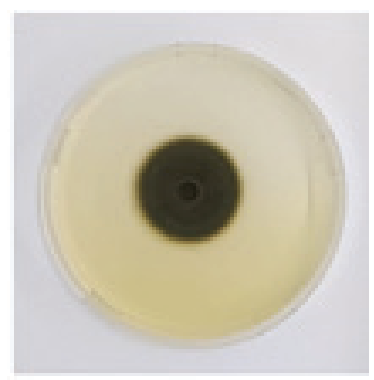

D

Figure 1. Growth inhibition of Curvularia lunata BM on potato dextrose agar (PDA)-filtrate medium: A. control, B. 12 days, C. 14 days, D. 16 days.

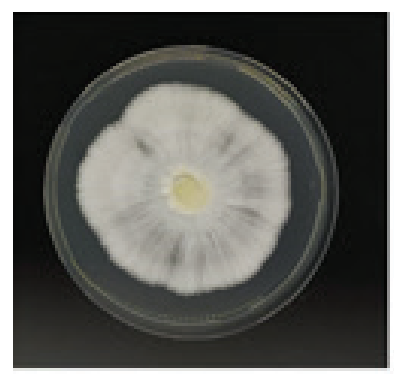

A

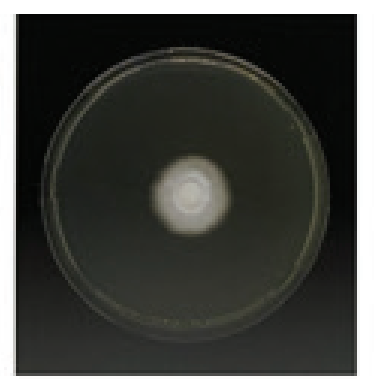

B

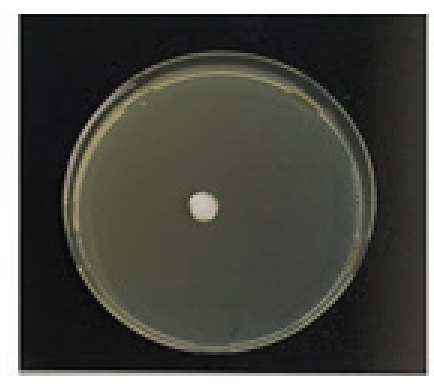

C

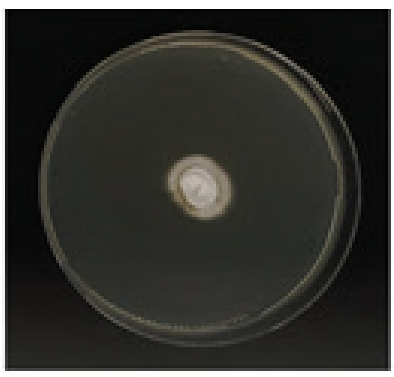

D

Figure 2. Growth inhibition of Ganoderma sp. TB4 on potato dextrose agar (PDA)-filtrate medium: A. control, B. 12 days, C. 14 days, D. 16 days. 
Table 1. Antibiosis agar assay of Bacillus siamensis LDR against fungal pathogens.

\begin{tabular}{|c|c|c|c|c|c|c|c|c|}
\hline \multirow[t]{2}{*}{ Fungal Pathogen } & \multirow[t]{2}{*}{ Repetition } & \multirow[t]{2}{*}{ Control (mm) } & \multicolumn{2}{|c|}{12 days } & \multicolumn{2}{|c|}{14 days } & \multicolumn{2}{|c|}{16 days } \\
\hline & & & Treatment $(\mathrm{mm})$ & GIR (\%) & Treatment $(\mathrm{mm})$ & GIR (\%) & Treatment $(\mathrm{mm})$ & GIR (\%) \\
\hline \multirow[t]{6}{*}{ Curvularia lunata BM } & 1 & 69.90 & 37.68 & 46.10 & 37.22 & 46.75 & 38.80 & 44.49 \\
\hline & 2 & & 41.33 & 40.87 & 36.91 & 47.20 & 37.42 & 46.47 \\
\hline & 3 & & 38.57 & 44.83 & 37.32 & 46.61 & 37.10 & 46.93 \\
\hline & 4 & & 39.20 & 43.92 & 36.75 & 47.43 & 36.89 & 47.23 \\
\hline & 5 & & 38.46 & 44.98 & 36.76 & 47.41 & 37.55 & 46.29 \\
\hline & average & & $39.05 \pm 1.39$ & $44.14 \pm 1.98$ & $36.99 \pm 0.26$ & $47.08 \pm 0.38$ & $37.55 \pm 0.75$ & $46.28 \pm 1.07$ \\
\hline \multirow[t]{6}{*}{ Ganoderma sp. TB4 } & 1 & 61.19 & 28.83 & 52.89 & 8.81 & 85.60 & 23.18 & 62.12 \\
\hline & 2 & & 30.83 & 49.61 & 8.26 & 86.50 & 25.26 & 58.72 \\
\hline & 3 & & 29.90 & 51.13 & 9.43 & 84.59 & 20.83 & 65.96 \\
\hline & 4 & & 28.28 & 53.78 & 7.89 & 87.11 & 23.59 & 61.44 \\
\hline & 5 & & 29.07 & 52.49 & 8.48 & 86.14 & 22.53 & 63.19 \\
\hline & average & & $29.38 \pm 1.00$ & $51.98 \pm 1.63$ & $8.57 \pm 0.58$ & $85.99 \pm 0.95$ & $23.08 \pm 1.61$ & $62.28 \pm 2.64$ \\
\hline
\end{tabular}

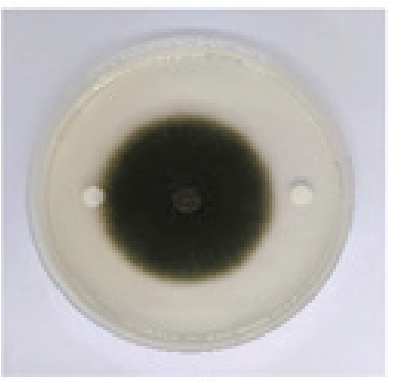

$\mathbf{A}$

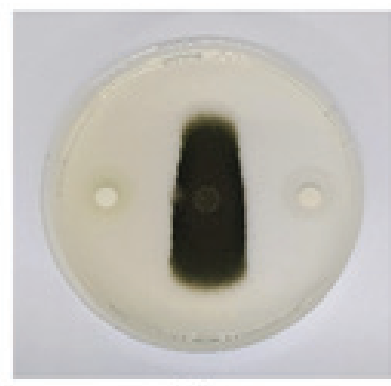

B

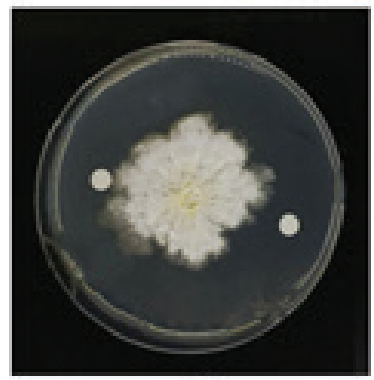

C

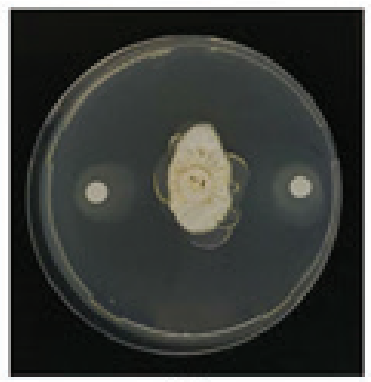

D

Figure 3. Growth inhibition of Curvularia lunata BM: A. control, B. treatment; Ganoderma sp. TB4 : C. control; D. treatment caused by the crude extract of Bacillus siamensis LDR.

Table 2. Antifungal assay of the crude extract from Bacillus siamensis LDR.

\begin{tabular}{|c|c|c|c|c|}
\hline \multirow{3}{*}{ Fungal Pathogen } & \multicolumn{4}{|c|}{ Radius (mm) } \\
\hline & \multirow[t]{2}{*}{ Repetition } & & & \multirow[t]{2}{*}{ GIR (\%) } \\
\hline & & Control & Treatment & \\
\hline \multirow[t]{5}{*}{ Curvularia lunata BM } & 1 & 35.53 & 12.64 & 56.03 \\
\hline & 2 & & 10.01 & 65.18 \\
\hline & 3 & & 11.43 & 60.24 \\
\hline & 4 & & 11.11 & 61.36 \\
\hline & Average & & $11.30 \pm 1.08$ & $60.70 \pm 3.76$ \\
\hline \multirow[t]{5}{*}{ Ganoderma sp. ТВ4 } & 1 & 32.58 & 9.81 & 60.24 \\
\hline & 2 & & 7.60 & 69.21 \\
\hline & 3 & & 8.23 & 66.64 \\
\hline & 4 & & 8.66 & 64.90 \\
\hline & Average & & $8.58 \pm 0.93$ & $65.25 \pm 3.78$ \\
\hline
\end{tabular}

Table 3. Retention factor of protein moiety in antifungal compounds detected using TLC.

\begin{tabular}{lcc}
\hline & Spot & Rf value \\
\hline A & 0.89 \\
B & 0.69 \\
C & 0.64 \\
D & 0.40 \\
E & 0.37 \\
\hline
\end{tabular}

five spots with pink and yellow color (Fig. 4b), labeled A to E, with $\mathrm{Rf}$ values ranging from 0.37 to 0.89 (Table 3 ) indicating a protein moiety of the compound. The spot $\mathrm{B}(\mathrm{Rf}=0.69)$ was the most dense pink color; meanwhile the spot $\mathrm{E}(\mathrm{Rf}=$ 0.37 ) was quite distinguish with a yellowish color (Fig. 4b).

According to Habib et al. (2020), the appearance of redto-pink spots indicates the presence of lipopeptides in the crude extract. The pink color on the TLC plate indicated

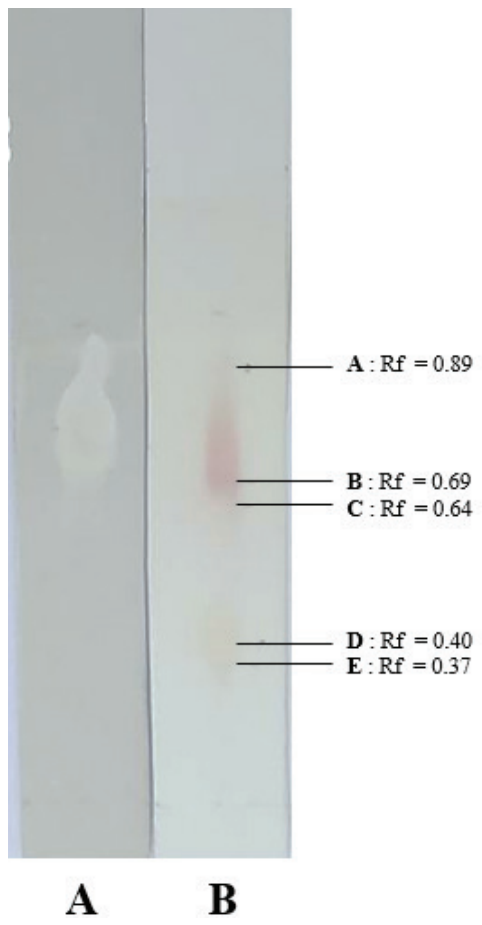

Figure 4. Thin layer chromatography of crude extract Bacillus siamensis LDR : A. lipid moiety; B. protein moiety.

that amino acids were contained in the extract (Hussain and Khan 2020). Therefore, it indicated the antifungal activity of the crude extract of $B$. siamensis LDR appeared to be due to a group of lipopeptide compounds.

The chromatogram profile of the crude extract of B. siamensis LDR are shown in Fig. 5. The extract contained 


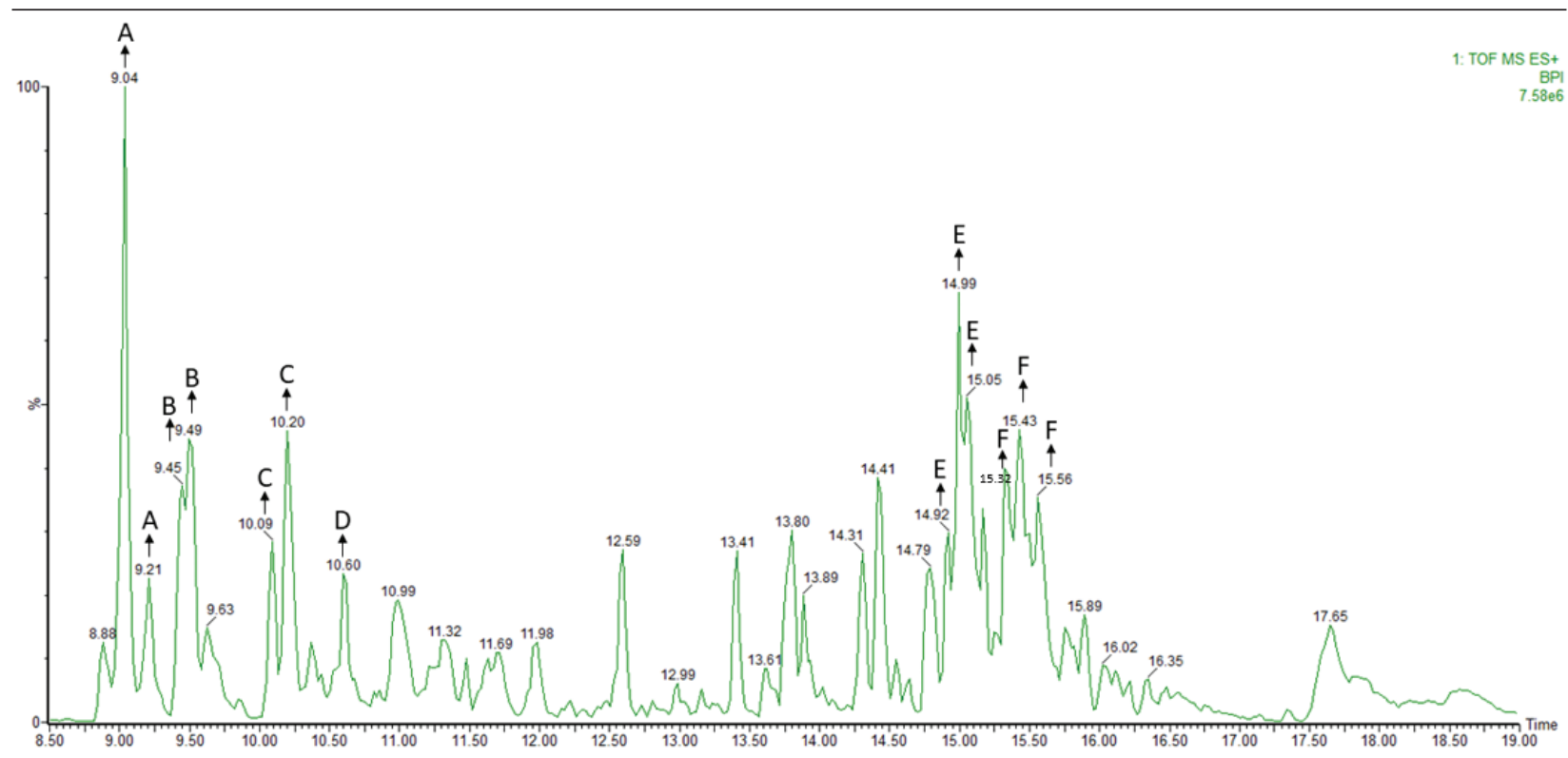

Figure 5. The chromatogram profile of the crude extract of Bacillus siamensis LDR : A. $\mathrm{C}_{14}$ iturin A; B. $\mathrm{C}_{14}$ bacillomycin F; C. $\mathrm{C}_{15}$ bacillomycin F; D. $\mathrm{C}_{16}$ bacillomycin F; E. $\mathrm{C}_{12}$ surfactin; F. $\mathrm{C}_{13}$ surfactin.
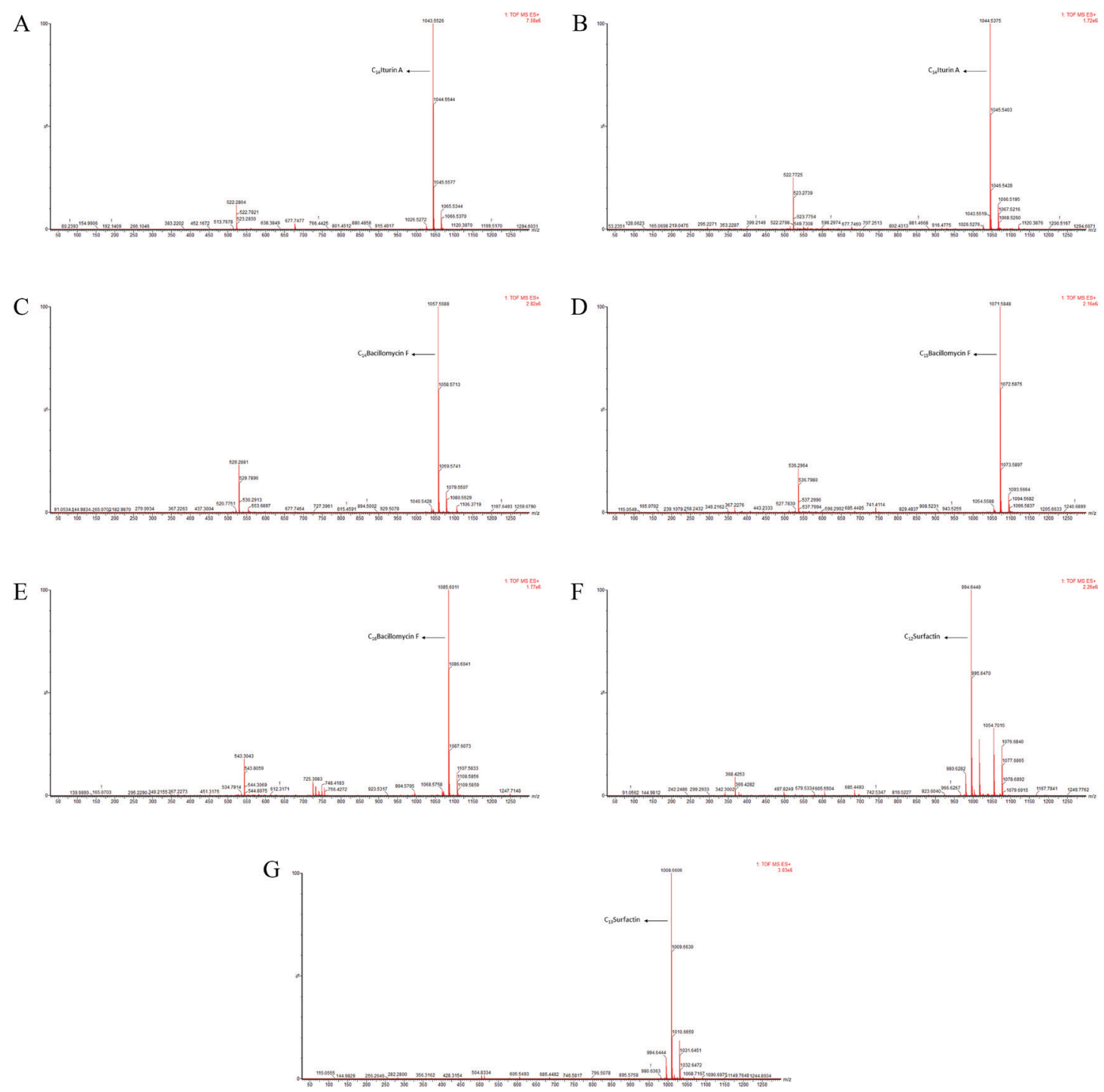

Figure 6. The results of mass spectrometry analysis: A. $\mathrm{C}_{14}$ iturin A $\left(\mathrm{m} / z\right.$ 1043.5526); B. $\mathrm{C}_{14}$ iturin A $\left(\mathrm{m} / z\right.$ 1044.5375); C. $\mathrm{C}_{14}$ bacillomycin F ( $m / z$ 1057.5688); D. $C_{15}$ bacillomycin F ( $/ 2 / z$ 1071.5848); E. $C_{16}$ bacillomycin F $(\mathrm{m} / z$ 1085.6011); F. C 12 surfactin $(m / z$ 994.6440); and G. $C_{13}$ surfactin $(m / z$ 1008.6606) 
Table 4. Mass spectrometry results for the crude extract.

\begin{tabular}{|c|c|c|c|c|c|c|c|}
\hline Peak No & RT & $m / z(\mathrm{M}+\mathrm{H})^{+}$ & Compound & Peak No & RT & $m / z(\mathrm{M}+\mathrm{H})^{+}$ & Compound \\
\hline 1 & 9.04 & 1043.5526 & $\mathrm{C}_{14}$ Iturin $\mathrm{A}$ & 8 & 14.92 & 994.6440 & $\mathrm{C}_{12}$ Surfactin \\
\hline 2 & 9.21 & 1044.5375 & $\mathrm{C}_{14}$ Iturin $\mathrm{A}$ & 9 & 14.99 & 994.6434 & $\mathrm{C}_{12}$ Surfactin \\
\hline 3 & 9.45 & 1057.5688 & $\mathrm{C}_{14}$ Bacillomycin F & 10 & 15.05 & 994.6451 & $\mathrm{C}_{12}$ Surfactin \\
\hline 4 & 9.49 & 1057.5687 & $\mathrm{C}_{14}$ Bacillomycin F & 11 & 15.32 & 1008.6606 & $\mathrm{C}_{13}$ Surfactin \\
\hline 5 & 10.09 & 1071.5848 & $\mathrm{C}_{15}$ Bacillomycin $\mathrm{F}$ & 12 & 15.43 & 1008.6603 & $\mathrm{C}_{13}$ Surfactin \\
\hline 6 & 10.20 & 1071.5859 & $\mathrm{C}_{15}$ Bacillomycin $\mathrm{F}$ & 13 & 15.56 & 1008.6616 & $\mathrm{C}_{13}$ Surfactin \\
\hline 7 & 10.60 & 1085.6011 & $\mathrm{C}_{16}$ Bacillomycin $\mathrm{F}$ & & & & \\
\hline
\end{tabular}

32 different compounds eluting at 8.88 to $18.57 \mathrm{~min}$. Based on the mass spectrometry analysis of the molecular ions $[\mathrm{M}+\mathrm{H}]^{+}$data and the comparison of the findings from previous studies by Xu et al. (2018) and Gorai et al. (2021), it was showed that 13 peaks were tentatively identified as $\mathrm{C}_{14}$ iturin A (Rt 9.04 and 9.21), $C_{14}$ bacillomycin F (Rt 9.45 and 9.49), $\mathrm{C}_{15}$ bacillomycin F (Rt 10.09 and 10.20), $\mathrm{C}_{16}$ bacillomycin $\mathrm{F}$ (Rt 10.60), $C_{12}$ surfactin (Rt 14.92, 14.99, and 15.05), and $C_{13}$ surfactin (Rt 15.32, 15.43, and 15.56) (Table 4). The MS profiles of iturin A, bacillomycin $\mathrm{F}$, and surfactin are shown in Fig. 6. Those annotation compounds were mostly detected as the major peaks of the present extract (Fig. 5). Indeed, they constitute the common antifungal compounds produced by Bacillus species and are cyclic lipopeptides (Kumar and Johri 2012; Dame et al. 2021). Another research by Ali et al. (2020) reported that iturin and surfactin was also detected in $B$. siamensis S3 extract at $m / z 1023.6$ to 1122.7 using MALDI-TOF mass spectrometry. Sharma et al. (2021) also reported surfactin and bacillomycin $(\mathrm{m} / \mathrm{z} 994.8$ to 1096.86$)$ that has been isolated from $B$. siamensis NKIT9 extract. All the given studies showed that the B. siamensis commonly produced lipopeptide biosurfactant, such as iturin and surfactin.

\section{Conclusion}

Bacillus siamensis LDR can produce antifungal compounds when grown in a modified $\mathrm{CDB}$ medium with hanjeli starch as the carbon source. The antifungal compounds can inhibit the growth of both C. lunata BM and Ganoderma TB4. The percentage inhibition by a crude extract containing the antifungal compounds was up to $60.70 \%$ for C. lunata BM and $65.25 \%$ for Ganoderma sp. TB4. The crude extract apparently contained several antifungal compounds, including iturin A, bacillomycin F, and surfactin.

\section{Acknowledgments}

This research was supported by the Ministry of Research and Technology/National Agency Research and Innovation, with funding from a grant Penelitian Dasar Unggulan Perguruan Tinggi (No. NKB-172/UN2.RST/HKP.05.00/2021) to Iman Santoso. We are grateful to Collaboration Lab Merck-FMIPA UI for supporting our research.

\section{References}

Abdallah RAB, Jabnoun-Khiareddine H, Mokni-Tlili S, Medimagh-Saidana S, Daami-Remadi M (2015) Endophytic Bacillus spp. from wild solanaceae and their antifungal potential against Fusarium oxysporum f. sp. lycopersici elucidated using whole cells, filtrate cultures and organic extracts. Journal of Plant Pathology \& Microbiology 6: 1-7. http://dx.doi.org/10.4172/2157-7471.1000324

Agustika, D, Prihartna C, Suwanto A (2019) Rapid inoculation technique and biological control of leaf spot disease in oil palm. International Journal of Oil Palm 2: 1-11. https://doi.org/10.35876/ijop.v2i1.24

Akinrinlola RJ, Yuen RY, Drijber RA, Adesemoye AO (2018) Evaluation of Bacillus strains for plant growth promotion and predictability of efficacy by in vitro physiological traits. International Journal of Microbiology 2018: 1-11. https://doi.org/10.1155/2018/5686874

Ali MA, Ren H, Ahmed T, Luo J, An Q, Qi X, Li B (2020) Antifungal effects of rhizospheric Bacillus species against bayberry twig blight pathogen Pestalotiopsis versicolor. Agronomy 10: 1-16. https://doi. org/10.3390/agronomy10111811

Almeida F, Rodrigues ML, Coelho C (2019) The still underestimated problem of fungal iseases worldwide. Frontiers in Microbiology 10 1-5. https://doi.org/10.3389/fmicb.2019.00214

Corke H, Huang Y, Li JS (2016) Coix: Overview. In: Wrigley C, Corke H, Seetharaman K, Faubion J (Eds) Encyclopedia of Food Grains $2^{\text {nd }}$ edn.: The World of Food Grains. Oxford, Academic Press, 184-189. https://doi.org/10.1016/B978-0-12-394437-5.00008-5
Dame ZT, Rahman M, Islam T (2021) Bacilli as sources of agrobiotechnology: recent advances and future directions. Green Chemistry Letters and Reviews 14: 246-271. https://doi.org/10.1080/17518253.20 21.1905080

Fadhilah QG, Santoso I, Maryanto AE, Yasman (2021) Antifungal potential from Bacillus sp. Against phytopathogenic fungus Colletotrichum sp. AIP Conference Proceedings 2374: 1-8. https:// doi.org/10.1063/5.0058769

FAO [Food and Agriculture Organization of the United Nations] (2017) Country fact sheet on food and agriculture policy trends: Indonesia: Socio-economic context and role agriculture. https://www.fao.org/3/ i7696e/i7696e.pdf [Accessed on: 29.12.2021]

Garcia-Aroca T, Doyle V, Singh R (2018) First report of Curvularia leaf spot on corn, caused by Curvularia lunata, in the United States. Plant Health Progress 19: 140-142. https://doi.org/10.1094/PHP-02-180008-BR

Gorai PS, Ghosh R, Mandal S, Ghosh S, Chatterjee S, Gond SK, Mandal NC (2021) Bacillus siamensis CNE6- a multifaceted plant growth promoting endophyte of Cicer arietinum L. having broad spectrum antifungal activities and host colonizing potential. Microbiological Research 252: 1-12. https://doi.org/10.1016/j.micres.2021.126859

Habib S, Ahmad SA, Johari WLW, Shukor MYA, Alias SA, Smykla J, Saruni NH, Razak NSA, Yasid NA (2020) Production of Lipopeptide biosurfactant by a hydrocarbon-degrading Antarctic Rhodococcus. 
International Journal of Molecular Sciences 21: 1-21. https://doi. org/10.3390/ijms 21176138

Horak I, Engelbrecht G, Jansen van Rensburg PJ, Claassens (2019) Microbial metabolomics: essential definitions and the importance of cultivation conditions for utilizing Bacillus species as bionematicides. Journal of Applied Microbiology 127: 326-343. https://doi. org/10.1111/jam.14218

Hushiarian R, Yusof NA, Dutse SW (2013) Detection and control of Ganoderma boninense: strategies and perspectives. Springerplus 2: 1-12. https://dx.doi.org/10.1186\%2F2193-1801-2-555

Hussain T, Khan AA (2020) Determining the antifungal activity and characterization of Bacillus siamensis AMU03 against Macrophomina phaseolina (Tassi) Goid. Indian Phytopathology 73: 507-516. https:// doi.org/10.1007/s42360-020-00239-6

Kumar A, Saini S, Wray V, Nimtz M, Prakash A, Johri BN (2012) Characterization of an antifungal compound produced by Bacillus sp. strain A5F that inhibits Sclerotinia sclerotiorum. Journal of Basic Microbiology 52: 1-9. https://doi.org/10.1002/jobm.201100463

Kumar A, Johri BN (2012) Antimicrobial lipopeptide of Bacillus: natural weapon for biocontrol of plant pathogens. In: Satyanarayana T, Johri BN, Prakash A (Eds) Microorganisms in Sustainable Agriculture and Biotechnology. Springer, Netherlands, 91-111. https://doi. org/10.1007/978-94-007-2214-9

Kusanggraeni I, Santoso I, Yasman (2021) Antifungal production of Bacillus siamensis LDR against Aspergillus niger ABP and ART using rice starch as carbon source. Ecology, Environment and Conservation 27: S101-S107. http://www.envirobiotechjournals. com/article_abstract.php?aid=11129\&iid=324\&jid=3

Majeed RA, Shahid AA, Ashfaq M, Saleem MZ, Haider MS (2015) First report of Curvularia lunata causing brown leaf spots of rice in Punjab, Pakistan. Disease Note. https://doi.org/10.1094/PDIS-05-15-0581-PDN

Meena KR, Tandon T, Sharma A, Kanwar SS (2018) Lipopeptide antibiotic production by Bacillus velezensis KLP2016. Journal of Applied Pharmaceutical Science 8: 091-098. http://dx.doi.org/10.7324/ JAPS.2018.8313

Mulyono E, Kusuma A, Dewandari KT, Darniadi S (2019) Preliminary study of hanjeli (Coix lacryma-jobi L) flour for food uses. IOP Conference Series: Earth and Environmental Science 309: 1-6. https:// doi.org/10.1088/1755-1315/309/1/012057

Naher L, Yusuf UK, Tan SG, Ismail A (2013) Ecological status of Ganoderma and basal stem rot disease of oil palms (Elaeis guineensis Jacq.) Australian Journal of Crop Science 7: 1723-1727. http://www. cropj.com/naher_7_11_2013_1723_1727.pdf

Pertiwi M, Santoso I, Fadhilah QG (2021) Antagonistic activity screening of Bacillus siamensis LDR against fungal associated with crop contamination. IOP Conference Series: Earth and Environmental Science 846: 1-7. https://doi.org/10.1088/17551315/846/1/012002

Peterson RRM (2019) Ganoderma boninense disease of oil palm to significantly reduce production after 2050 in Sumatra if projected climate change occurs. Microorganisms 7: 1-8. https://doi.org/10.3390/ microorganisms7010024

Prapagdee B, Kuekulvog C, Mongkulsuk S (2008) Antifungi potential of extracellular metabolites produced by Streptomyces hygrospicus against phytophatogenic fungi. International Journal of Biological Science 4: 330-337. https://doi.org/10.7150/ijbs.4.330

Radhakrishnan R, Hashem A, Abd_Allah EF (2017) Bacillus: a biological tool for crop improvement through bio-molecular changes in adverse environments. Frontiers in Physiology 8: 1-14. https://doi. org/10.3389/fphys.2017.00667

Rees RW, Flood J, Hasan Y, Potter U, Cooper RM (2009) Basal stemrot of oil palm (Elaeis guineensis); mode of root infection and lower stem invasion by Ganoderma boninense. Plant Pathology 58: 982-989. https://doi.org/10.1111/j.1365-3059.2009.02100.x

Safitri SD, Santoso I, Fadhilah QG, Maryanto AE, Yasman (2021) Antagonistic activity of Bacillus siamensis LDR against Curvularia lunata BM. AIP Conference Proceedings, in press.

Santoso I, Fadhilah QG, Maryanto AE, Yasman (2021a) Antagonist effect of Bacillus spp. against Aspergillus niger CP isolated from cocopeat powder. IOP Conference Series: Earth and Environmental Science 846: 1-10. https://doi.org/10.1088/1755-1315/846/1/012001

Santoso I, Fadhilah QG, Maryanto AE, Yasman (2021b) The potency of Bacillus siamensis LDR as biocontrol agent against fungal phytopathogen. Advances in Biological Sciences Research 14: 463-468. https://dx.doi.org/10.2991/absr.k.210621.079

Shafi J, Tian H, Ji M (2017) Bacillus species as versatile weapons for plant pathogens: a review. Biotechnology \& Biotechnological Equipment 31: 446-459. https://doi.org/10.1080/13102818.2017.1286950

Sharma A, Kaushik N, Sharma A, Bajaj A, Rasane M, Shouche YS, Marzouk T, Djèbali N (2021) Screening of tomato seed bacterial endophytes for antifungal activity reveals lipopeptide producing Bacillus siamensis strain NKIT9 as a potential bio-control agent. Frontiers in Microbiology 12: 1-17. https://doi.org/10.3389/ fmicb.2021.609482

Sunpapao A, Kittimorakul J, Pornsuriya C (2014) Disease Note: Identification of Curvularia oryzae as cause of leaf spot disease on oil palm seedlings in nurseries of Thailand. Phytoparasitica 2: 1-6. https://doi. org/10.1007/s12600-014-0390-9

Tensiska, Cahyana Y, Nurhadi B, Desani, WD, Subroto E (2021) In vitro digestibility and the characteristics of puffed products from different degrees of milling and moisture content of adlay grain (Coix lacryma-jobi L.). Food Research 5: 317-378. http://dx.doi. org/10.26656/fr.2017.5(2).548

Tiwari S, Prasad V, Lata C (2019) Bacillus: plant growth promoting bacteria for sustainable agriculture and environment. In: Singh JS, Singh DP (Eds) New and Future Developments in Microbial Biotechnology and Bioengineering: Microbial Biotechnology in Agro-Environmental Sustainability. Elsevier, The Netherlands, 43-45. https://doi. org/10.1016/B978-0-444-64191-5.00003-1

Wang X, Conway PL, Brown IL, Evans AJ (1999) In vitro utilization of amylopectin and high-amylose maize (amylomaize) starch granules by human colonic bacteria. Applied and Environmental Microbiology. 65: 4848-4854. https://doi.org/10.1128/aem.65.11.48484854.1999

Xu B, Lu Y, Ye Z, Zheng Q, Wei T, Lin J, Guo L (2018) Genomics-guided discovery and structure identification of cyclic lipopeptides from the Bacillus siamensis JFL15. PLoS ONE. 13: 1-18. https://doi. org/10.1371/journal.pone.0202893 